\title{
Definitions of Criminal Assessments, Their Content and Legal Basis in Russian Criminal Science
}

\author{
${ }^{1}$ Ildar A. Tarkhanov, ${ }^{2}$ Ramil R. Gayfutdinov \\ ${ }^{1,2}$ Kazan Federal University \\ Email: gayfutdinov.r@yandex.ru
}

\section{Received: 02 ${ }^{\text {nd }}$ November 2018, Accepted: $28^{\text {th }}$ November 2018, Published: $31^{\text {st }}$ December 2018}

\begin{abstract}
The paper discusses various doctrinal definitions of the criminal assessment of a crime and their correspondence to the actual content of this type of law enforcement activity. Any approach to the characterization of the concept under consideration has a rational kernel. More preferred is a comprehensive assessment of the criminal law phenomenon under consideration. The authors give their own definition for criminal assessments; they identify four logical-legal operations of different nature, which constitute its content. Based on the analysis of criminal law and procedural sources, they formulate modern approaches to the definition of the algorithm of law enforcement operations. The problem of the legal basis for assessing crimes is also critically analyzed.
\end{abstract}

\section{Keywords}

Law Enforcement Activity, Criminal Law Assessment of an Offense, Criminal Assessment, Stages, Content, Legal Basis

\section{Introduction}

The problematics of the study of the theoretical foundations for criminal assessment upon the legal assessment of an offense are of interest not only for representatives of national science, but is also actively discussed in the pages of foreign journals [1]. We meet such discussions about various problems of assessing crimes when studying foreign literature [2]. At the same time, there are no clear positions about it concerning the issues of its definition, content and fundamentals [3].

There are different approaches to defining the criminal assessment in the Russian criminal law literature. The basis of many modern definitions is the definition proposed by the academician, doctor of law, professor V.N. Kudryavtsev. He formulated it as "establishing and legally fixing the exact correspondence between the actual signs of the committed act and the signs of the crime, provided for by the criminal law" [6]. The essence of the concept we are considering quite accurately determines the nature and content of this activity and its results: the qualifier extracts legally significant signs of the act, compares them with the legislative description of the crime, and concludes, as a result, fixes it in the form of a decision set out in a certain criminal procedure. Therefore, this definition can be the basis for characterizing this type of law enforcement, as well as for defining the criminal assessment as a universal concept.

\section{Methods}

The basis of the research is the dialectical method of scientific knowledge, general scientific (analysis, synthesis, deduction, induction, systemic structural) and special scientific (formal legal and comparative legal) methods.

\section{Results and Discussion}

1. The advantage of the concept put forward by V.N. Kudryavtsev is, firstly, that assessment is considered simultaneously as a process and as its result. The scientist reveals the content of this process through the term "determination" which becomes a sign of the definition, by which the active side of assessment is accentuated, first of all: a) the identification of specific criminal characteristics of the offense on the basis of established factual circumstances b) determination of the elements essential to the offence, stated in the criminal law and pretending for use, c) their comparison with each other. The result of this legal operation is the conclusion about the exact correspondence of the objects of research being compared, which has the nature of a decision.

It should be noted that the attribute "legal confirmation" contained in the analyzed definition is not peculiar to any type of crime assessment: not only authorized subjects, but also other persons not related to jurisprudence as a profession (unofficial assessment) carry out criminal assessments. The legal confirmation of a conclusion is made in the corresponding law enforcement act. With its unofficial kind, the conclusion about the coincidence (identity) can also be registered in oral or written forms, but not in the criminal procedure document. At the same time, unofficial assessments can be doctrinal, professional, and common.

When characterizing the criminal assessment, it should be borne in mind that at the core of its understanding, its core is criminal law assessment. Some scientists consider it a generic feature of the concept defined here [7]. R. A. Sabitov is right in believing that the concept of "criminal legal assessment" can also be used in defining a number of more general or particular concepts [8]. The criminal assessment is one of the types of criminal law assessment of a phenomenon based on criminal law (or ideas about its content) [9].

When characterizing the definition of a criminal assessment that has become traditional and common, attention is usually drawn to the fact that the term (and attribute) of "determination" bears in the definition of only the procedural (activity) 
burden, and its effective aspect is indicated by fixing the conclusion in the relevant law enforcement act. In the definition of assessment, the term "determination" (and the corresponding attribute) combines both active and effective aspects. From an etymological point of view, "to determine" means not only proving, figuring out, but also detecting [10]. Consequently, any kind of criminal assessment can be considered as a determination of an exact correspondence between the signs of the committed act and the signs of the crime, including the conclusion about their correspondence. The sign "legal confirmation" should be considered additional, for it is inherent only in the official type of assessment as a type of law enforcement activity. The conclusion about the compliance of the compared objects with informal assessment always takes place as a kind of decision, but does not entail formal consequences. This conclusion allows us to develop a definition common to all types of assessments of crimes.

In the criminal law literature, often the objects of a comparative study in assessing a crime are the actual (real) evidences of the offense and the evidence of the crime. Such an approach cannot be considered justified from a methodological (philosophical) point of view. It is impossible to establish the identity or at least the exact correspondence between the actual signs of the act and the criminal law signs of the crime composition without prior activities to extract legally significant features from the factual basis (factual data). This is an activity of transforming social facts into a comparable (legal) form. Recognizing the need for this logical-legal operation, some scientists do not include it in the content of the criminal assessment believing that this is a prerequisite for assessment, an activity preceding it [11]. Thus, the official criminal assessment is the establishment of the identity between the legally significant signs of the committed act and the signs of a certain offense under the criminal law and its other provisions, with its subsequent fixation in the established criminal procedure form.

2. The content of the official criminal assessment in procedural terms is a set of logical-legal operations and the corresponding criminal legal assessments carried out by a law enforcement officer during the final criminal legal assessment of the criminal offense committed as a certain type of criminal offense. In the theory of criminal law, they are sometimes called the stages of criminal assessment, and they are often associated with the stages of a criminal process [12]. We share the point of view of Professor A.I. Rarog, who believes that the content of the criminal assessment should be distinguished from such stages, since the same logical-legal operations are carried out at each procedural stage when qualifying a crime [13].

The literature suggests other approaches to phasing the process of assessing a crime [14]. They have much in common, although they differ in their individual components. In our opinion, the process of assessing a crime should be presented as follows as a set of logical-legal operations following one after another [15].

2.1 The first stage in the criminal assessment consists in extracting the legally significant features proved in the case from the totality of the actual ones. This allows us to bring the plot of the case in a legal form. They are called legal wording in the structure of the charges in the substantive sense. Only in this case it is possible to solve the problem of establishing the desired identity (exact match). Some experts believe that the initial stage of assessing a crime is to establish the actual circumstances of the case. However, as V. N. Kudryavtsev quite rightly believed, such activity is only a prerequisite for the correct application of the rule of law [16]. In the criminal process, it is called proving. In this sense, a criminal assessment is a criminal assessment of proven facts.

2.2. At the next stage, a criminal law base is created as the intended legal basis for the future comparison of the identified and legally significant indications of the act with the elements of the crime claiming to be applied. It thus constitutes a certain aggregate of offenses. The criminal law base is formed by the putting forward of assessment versions as legal hypotheses.

2.3. At the next stage, the logical-legal operation of comparing the legally significant signs of an offence with signs of the elements of crimes that are included in the criminal law base is carried out. In other words, a) the determination of the presence or absence of an exact match between legally significant signs of an offence and the corresponding objective and subjective signs of individual offenses, b) the process of exclusion of certain constituent elements of offences from the previously formed criminal law framework.

2.4. As a result of such a comparison, it is concluded that the legally relevant features fully correspond to the characteristics of certain constituent elements of the offence (or to the sets of constituent elements - with a plurality of crimes). It completes the procedure for establishing the exact correspondence (identity) to the objects of study being compared.

As noted earlier, the method of recording of a conclusion formulated in a certain form is associated with the peculiarities of the subject under assessment. With the official assessment of the crime, the conclusion about the identity is recorded in the procedural act established by the Criminal Procedure Code of the Russian Federation (hereinafter - the Code of Criminal Procedure of the Russian Federation), for example, in the indictment, or crime bill.

In the theory of law there is a discussion on the legal nature of the criminal assessment. According to the majority of domestic scientists, this is a criminal law category. However, the idea is expressed that this is a complex phenomenon that has a criminal law and criminal procedure nature, since the official assessment is reflected in the appropriate criminal procedure form. This conceptual view contains some rational kernel, since legal assessment is a structural element of a charge in a material legal sense and is recorded, as already noted, in a certain form. The analyzed matters also allow us to consider the issue of assessing a crime in a slightly different and wider context. In the theory of criminal law, an understanding of the criminal assessment in a broad and narrow sense has actually taken shape, since sometimes such assessment is defined as a reference to an article (its part or paragraph) of the Criminal Code of the Russian Federation. 
The constituent elements of an offence are the case story, legal language and legal assessment [17]. Legal language and legal assessments have much in common, but they differ from each other. Strictly speaking, both legal wording and legal assessments are a criminal law assessment but are committed in a different form. This makes it possible to speak of the criminal assessment in its broad sense. Thus, the legal wording is only a description of all the signs of the offense enshrined in the criminal law norm without reference to the article (part, paragraph) of the Criminal Code of the Russian Federation.

The legal criminal assessment understood as a reference to an article of the Criminal Code of the Russian Federation, is determined by legal wording, but it may not completely coincide with it. Sometimes, when assessing a crime in its narrow sense, such a coincidence may not be, because, according to the rules of such assessment, in cases where there are several assessment signs for the offence, one of which is of particular importance for assessment, only the last one is referred to. 3. The problem of the basic assessments of crimes has several aspects: methodological, logical and legal. Therefore, in the literature there are philosophical (methodological), logical, psychological, legal (regulatory) frameworks for the criminal assessments [18]. In this case, the philosophical foundations are usually considered the categories of the general, the particular and the individual (separate), the essence and the phenomenon, the content and the form. A.V. Naumov and A. S. Novichenko considered an assessment as "a logical process of transition from the initial knowledge to the output one through justifying knowledge"[19]. According to R. A. Sabitov, the legal basis for the criminal assessment should be considered a set of norms that are used by a law enforcement officer for the criminal legal assessment of offences, and its grounds are constituent elements of offence [20]. Thus, in theory, an attempt is made to distinguish between the concepts of the "basis" and the "grounds" of a criminal assessment. Depending on this, we select the range of sources on which the law enforcer relies when assessing a crime.

It is sometimes proposed to consider either a criminal law (Criminal Code of the Russian Federation), or a criminal legal norm, or a corpus delicti, as a legal (judicial) basis for assessing a crime, the signs of which are contained in the Criminal Code of the Russian Federation [21]. Such a position is usually substantiated by the fact that in order to enshrine the result of assessing a crime, references to the clause, part and article of the corpus delicti are important, and in some cases references to the norms of its Common part. Each of these points of view has a rational kernel.

Indeed, it is the criminal law that is the legal basis for assessing a crime, since it contains criminal law norms, which, in turn, describe the characteristics of the relevant elements of the crime as legislative models for the criminal assessments [22]. In addition, prescriptions containing a number of normative rules for the assessment of the law, are necessary for the criminal assessments in special forms of criminal activity (uncompleted criminal activity, complicity in crime, their multiplicity and others that contribute to the disclosure of the elements of crime: the concept of subject, guilt, etc.). Thus, the corpus delicti being the legal basis for assessing a crime, is not its only source. R. A. Sabitov believes that the legal basis of criminal legal assessments is the sources of criminal law on which the assessment of acts and events, as well as other regulatory phenomena that are used in their criminal legal assessment, is based [23].

It is known that the dispositions of some criminal law norms, in which the signs of the corresponding offenses are formulated, are designed as blanket ones. When assessing acts of this kind, the law enforcer is forced to refer to the norms of other branches of law. The ambiguous attitude to these regulations as the legal basis for the criminal assessments has developed in the theory of criminal law. In our opinion, the norms of other branches of law constituting a legal framework cannot be an independent basis for assessing a crime, because reference to them is not made when an offence is assessed. They are necessary for the correct interpretation of the content of the relevant offenses.

\section{Summary}

As we noted, for the reason that the legal confirmation of a conclusion is inherent only in characterizing the official (legal) criminal assessment, the official criminal assessment is the determination of an identity between the legally significant signs of the committed offence and the signs of a certain crime envisaged by the criminal law and other provisions, with its subsequent consolidation in the established criminal procedure form.

In terms of content, the criminal assessment is possible to be divided into the following stages: 1) extracting from the totality of the actual legally significant (criminal-legal) grounds proven in the case; 2) the creation of a criminal law base; 3) comparison of legal significant signs of an offence with signs of the elements of crimes (and some norms of the General Part of the Criminal Code) that are included in the criminal law base; 4) the conclusion about the full compliance (identity) of legally significant signs with the signs of a certain constituent elements of the crime (or a set of a certain constituent elements - with a plurality of crimes).

The actual criminal law basis for the criminal assessment is a crime as a legislative model of a crime of a certain type, and in cases specified by law, also other legal instructions of the Criminal Code of the Russian Federation contained in its General Part.

\section{Conclusion}

Many of the problems we are discussing are debatable and sometimes pressing enough in the scientific world, which requires further joint discussions. Therefore, it is not by chance that, starting from the 60 s of the last century, the first works of the monographic level on the subject under study begin to appear, and the scientific discussion does not end to this day. 


\section{Acknowledgements}

The work is performed according to the Russian Government Program of Competitive Growth of Kazan Federal University.

\section{References}

[1] Card, Cross \& Jones Criminal Law, Twenty-second Edition, Richard Card and Jill Molloy, 888 p., 2016

[2] Criminal Law Theory: Doctrines of the General Part, Shute and Simester, eds, 332 p., 2002.

[3] Grant Lamond 'What is a Crime?', Oxford Journal of Legal Studies, Volume 27, Issue 4, 1 December 2007, Pages 609-632, https://doi.org/10.1093/ojls/gqm018.

[4] Dictionary of foreign words. M. : Russian language, 1988. Pp. 223.

[5] S. Jonson, A Russian Language, J. Rivington etc, 592 p., 1826.

[6] Kudryavtsev V.N. The theoretical basis for the criminal assessments // M. : Gosyurizdat, 1963. P. 8.

[7] See: V. Nikonov. Fundamentals of the Theory of the Criminal assessments (an algorithmic approach): study guide. Tyumen: Tyumen University Press, 2001.P. 24.

[8] See: R. Sabitov. Theory and practice of criminal assessments. M. : Yurlitinform, 2013. P. 27.

[9] See: L. Gaukhman. Criminal assessments: law, theory, practice. 3rd edition, revised and enlarged. M. : JurInfoR Center JSC, 2005. P. 6.

[10] Dictionary of the Russian language edited by S.I. Ozhegov and N.Yu. Shvedov. M., 1997. URL: http://dic.academic.ru/dic.nsf/ogegova/253790 (appeal date 07/17/17).

[11] See: R. Sabitov. The specified essay. P. 27.

[12] See: V. N. Kudryavtsev, General Theory of the Criminal assessments. M., 1999. Pp. 13-14; Kuznetsova N.F. Problems of criminal assessments: lectures on the special course "Basics of criminal assessments" / scientific editing and preface by academician V.N. Kudryavtsev. M. : Publishing House Gorodets 2007.Pp. 56, 58; Semerneva N. K. Criminal assessments ("General" and "Special" parts): a scientific and practical guide. M. : Prospectus; Ekaterinburg: USLA, 2014.Pp. 15 etc.

[13] Rarog A.I. Criminal assessments on subjective grounds.S.-Pb. : Legal Center Press, 2002.P. 24.

[14] See, for example: Lavygina I.V., Ostrovskikh Zh.V. Ten approaches to defining the stages of crime assessment. Russian Journal of Criminology, 2016, vol. 10, No. 4, pp. 721-731. DOI: 10.17150 / 2500- 4255.2016.10 (4).721-731.

[15] Tarkhanov I. A. Legal assessment: the concept and place in the law enforcement process // Russian legal journal. Ekaterinburg: USLA Publishing House, 2012.Number 3 (84). Pp. 134-138.

[16] Kudryavtsev V.N. The theoretical basis for the criminal assessments // M. : Gosyurizdat. 1963. P. 14.

[17] See: F.N. Fatkullin. Change of Prosecution. M. : Legal literature, 1971. Pp. 22-23.

[18] See: Criminal Law of Russia. Special part: Textbook / Edited by F. R. Sundurov, M.V. Talan. M. : Statute, 2012 . C. 20. (author of the chapter L. L. Kruglikov).

[19] See: A.V. Naumov, A.S. Novichenko. The laws of logic in the criminal assessments. M. : Legal literature, 1978. P. 76.

[20] See: R. Sabitov. Specified essay. P. 107.

[21] See: V.Duyunov, A.G. Khlebushkin. Ibid.

[22] See: I. Tarkhanov. Legal assessment: the concept and place in the law-enforcement process // Russian legal journal. Ekaterinburg: USLA Publishing House, 2012.Number 3 (84). P. 131.

[23] See: R. Sabitov. Specified essay. P. 120.

[24] A. Petrov, "General theory of relativity", Annalen der Physik, vol.49, no. 7, pp.769-822, 1916. 